\title{
GAMBARAN TINGKAT KECEMASAN ANAK TERHADAP PELAYANAN KESEHATAN GIGI DAN MULUT PADA SISWA/I KELAS V-B SD ST. ANTONIUS JL. SRIWIJAYA NO.7 MEDAN TAHUN 2014
}

\author{
Nelly Katharina Manurung \\ Jurusan Keperawatan Gigi Poltekkes Kemenkes Medan
}

\begin{abstract}
Abstrak
Rasa cemas terhadap pelayanan kesehatan gigi dan mulut sering dialami oleh setiap kalangan terutama pada anak - anak. Hal ini bisa disebabkan oleh trauma pada perawatan gigi sewaktu masa anak - anak dan bisa juga disebabkan oleh lingkungan sekitar. Penelitian ini bertujuan untuk melihat tingkat kecemasan yang dimiliki anak pada pelayanan kesehatan gigi dan mulut. Jenis penelitian yang digunakan adalah penelitian deskriptif dengan menggunakan metode survey. Sampel penelitian ini adalah seluruh siswa/i kelas V - B SD St. Antonius Jl. Sriwijaya No.7 Medan tahun 2014 yang berjumlah 42 anak. Data tentang kecemasan siswa/i diperoleh dari kuesioner yang dibagikan kepada seluruh sampel. Hasil yang diperoleh dari penelitian ini adalah $11,9 \%$ tidak cemas terhadap pelayanan kesehatan gigi dan mulut, 26,2\% memiliki tingkat kecemasan sedang, 33,3\% memiliki tingkat kecemasan yang tinggi dan 28,6\% sangat cemas terhadap pelayanan kesehatan gigi dan mulut. Penyebab kecemasan tertinggi adalah luka atau trauma pada rongga mulut $(52,4 \%)$ dan jenis pelayanan yang paling dicemaskan adalah pencabutan gigi $(47,2 \%)$.
\end{abstract}

Kata kunci : Kecemasan anak, Pelayanan Kesehatan Gigi dan Mulut

\section{Latar Belakang}

Kecemasan merupakan reaksi emosi sementara yang timbul pada situasi tertentu, yang dirasakan sebagai suatu ancaman (Cattell dan Scheiler dalam Izzaty, 2005). Kecemasan atau anxietas dapat pula diartikan sebagai rasa takut pada sesuatu tanpa sebab yang jelas, yang sering kali berlangsung lama. Kecemasan atau ketakutan mempunyai pola reaksi yang sama, yaitu menghindari objek.

Kecemasan pada anak dapat juga diakibatkan oleh beberapa hal, seperti orang tua yang terlalu melindungi (over protective), orang tua yang tidak konsisten, aturan atau disiplin yang terlalu berlebihan, kritikan yang terlalu berlebihan dari orang tua atau lingkungan sekitar, kurangnya sosialisasi anak terhadap orang lain dan adanya kegagalan atau frustasi yang terus menerus.

Salah satunya adalah rasa cemas pada perawatan gigi. Pada umumnya rasa takut timbul akibat pengalaman perawatan gigi yang buruk semasa kanak - kanak, oleh karena itu perlu diperhatikan bahwa pencegahan timbulnya rasa takut harus dimulai pada usia dini . Selain karena pengalaman buruk sewaktu perawatan gigi sebelumnya, rasa takut pada perawatan gigi juga bisa diakibatkan oleh pengaruh lingkungan misalnya keluarga (Mashar R, 2011).

Banyak orang tua yang memberikan pandangan bahwa unit pelayanan kesehatan gigi merupakan hukuman bagi anak, misalnya apabila anak malas untuk menyikat gigi anak akan dibawa ke dokter gigi lalu disuntik atau dicabut giginya. Hal ini tentu saja dapat merubah pola pikir anak yang menganggap mereka tidak perlu pergi ke unit pelayanan kesehatan gigi apabila mereka tidak membuat suatu kesalahan (Ramadhan A, 2010).

Rasa takut atau cemas terhadap perawatan gigi merupakan hambatan bagi tenaga kesehatan gigi dalam usaha peningkatan kesehatan gigi masyarakat yang sesuai dengan visi "Indonesia Sehat 2015". Oleh sebab itu sangat diharapkan tenaga kesehatan khususnya dalam bidang kesehatan gigi dan mulut perlu memahami sikap, sifat dan perilaku pasien anak pada setiap kelompok usia yang berguna untuk dokter gigi melakukan perawatan sehingga menunjang kelancaran dan keberhasilan perawatan.

Berdasarkan penelitian yang telah dilakukan sebelumnya oleh Astrid Anisa Amrullah , Bagian Ilmu Kesehatan Gigi Masyarakat Fakultas Kedokteran Gigi Universitas Hasanuddin Makassar tahun 2012, tingkat kecemasan anak usia 6, 9 dan 12 tahun berdasarkan CFSS - DS (Children Fear Survey Schedule - Dental Subscale) di Kecamatan yang mengalami rasa cemas tinggi sebanyak 37 anak $(11,6 \%)$.

Dari beberapa literature ditemukan bahwa insiden rasa takut terhadap perawatan kesehatan gigi terjadi kurang lebih $5 \%$ dari populasi dan diantaranya $16 \%$ pada anak anak usia sekolah. Hasil penelitian di Puskesmas Denpasar Barat menunjukkan gambaran rasa takut terhadap perawatan gigi pada anak usia sekolah yang berobat ke puskesmas, dari 91 anak yang berobat 5,49\% menyatakan 
tidak takut terhadap semua perawatan gigi, kemudian $8,79 \%$ menyatakan takut terhadap semua tindakan peraatan gigi dan $85,73 \%$ menyatakan takut terhadap beberapa tindakan perawatan gigi.

Penelitian ini dilakukan pada siswa/i kelas V SD (usia 10 - 11 tahun ) yang pada saat ini berada dalam Fase atau Masa Anak Sekolah atau disebut juga masa laten. Menurut Stone dan Church (1975) masa ini adalah masa kehilangan gigi, masa perubahan fisik yang cepat, masa meraih identitas yang tidak bergantung pada orang lain, masa untuk mengalami kelakuan dan berfikir realitik. Ini adalah masa terbaik untuk mengenalkan dan mengajarkan anak tentang kesehatan gigi (Parkin S.F, 1991).

\section{Tujuan Penelitian}

Penelitian ini bertujuan untuk mengetahui gambaran tingkat kecemasan anak terhadap pelayanan kesehatan gigi dan mulut pada siswa/i kelas V - B SD St. Antonius, Medan Tahun 2014.

\section{Manfaat Penelitian}

1. Hasil penelitian ini diharapkan dapat membantu tenaga kesehatan khususnya dalam bidang kesehatan gigi dalam memberikan pelayanan kesehatan gigi dan mulut pada pasien anak.

2. Hasil penelitian ini diharapkan dapat menambah bahan bacaan diperpustakaan bagi mahasiswa Jurusan Keperawatan Gigi Poltekkes Kemenkes Medan.

\section{Jenis dan Desain Penelitian}

Jenis penelitian ini adalah penelitian deskriptif dengan metode survey yang bertujuan untuk memperoleh gambaran tentang tingkat kecemasan anak terhadap pelayanan kesehatan gigi dan mulut di SD St. Antonius Jl. Sriwijaya No. 7, Medan.

\section{Lokasi Penelitian}

Peneltian ini dilakukan di SD St. Antonius Jl. Sriwijaya No. 7 Medan.

\section{Waktu Penelitian}

Peneltian ini dilakukan pada bulan September sampai dengan Oktober 2014

\section{Populasi Dan Sampel Penelitian}

Populasi adalah keseluruhan objek yang akan diteliti. Adapun populasi dalam penelitian ini adalah siswa/i kelas V - B SD St. Antonius, Jl. Sriwijaya No.7, Medan.

Sampel adalah sebagian yang diambil dari keseluruhan objek yang akan diteliti dan dianggap mewakili seluruh populasi. Dalam penelitian ini sampel yang di ambil sebanyak 42 siswa/i kelas V - B SD St. Antonius, Jl. Sriwijaya No.7, Medan.

\section{Hasil Penelitian}

Berdasarkan hasil penelitian yang dilakukan pada 42 siswa/i kelas V - B SD St. Antonius Jl. Sriwijaya No.7 Medan tahun 2014, data yang diperoleh dimasukkan ke dalam tabel distribusi frekuensi dan selanjutnya dilakukan analisa data.

Tabel A.1 Persentase Tingkat Kecemasan Anak Terhadap Pelayanan Kesehatan Gigi Dan Mulut Pada Siswa/I Kelas V - B SD St. Antonius Jl. Sriwijaya No.7 Medan Tahun 2014

\begin{tabular}{|c|c|c|}
\hline Tingkat Kecemasan & $\mathbf{n}$ & Persentase \\
\hline 1. Tidak cemas & 5 & $11,9 \%$ \\
\hline 2. Sedang & 11 & $26,2 \%$ \\
\hline 3. Tinggi & 14 & $33,3 \%$ \\
\hline 4. Sangat Cemas & 12 & $28,6 \%$ \\
\hline Jumlah & 42 & $100 \%$ \\
\hline
\end{tabular}

Dari tabel di atas dapat di lihat bahwa 33,3\% (14 orang) siswa/i kelas V - B SD St. Antonius Jl. Sriwijayan No. 7 Medan tahun 2014 memiliki tingkat kecemasan yang tinggi terhadap pelayanan kesehatan gigi dan mulut dan hanya $11,9 \%$ (5 orang) yang tidak cemas sama sekali terhadap pelayanan kesehatan gigi dan mulut. 
Tabel A.2 Distribusi Frekuensi Penyebab Kecemasan Anak Kelas V - B SD St. Antonius Jl. Sriwijaya No.7 Medan Tahun 2014 Terhadap Pelayanan Kesehatan Gigi Dan Mulut

\begin{tabular}{|c|c|c|c|c|}
\hline \multirow{3}{*}{ Jenis Kecemasan } & \multicolumn{4}{|c|}{ Tingkat Kecemasan } \\
\hline & 1 & 2 & 3 & 4 \\
\hline & Tidak Cemas & Cemas & Sangat Cemas & Tidak Tahu \\
\hline Suara atau getaran bur & 17 & 20 & 5 & 0 \\
\hline Suntikan untuk dibius & 8 & 14 & 20 & 0 \\
\hline Belum merasakan efek bius ( belum merasa kebas ) & 11 & 19 & 12 & 0 \\
\hline Perasaan kebas pada saat dibius & 10 & 14 & 18 & 0 \\
\hline Pengukuran kedalaman gusi & 14 & 22 & 6 & 0 \\
\hline $\begin{array}{l}\text { Suara atau perasaan ngilu pada saat membersihkan } \\
\text { gigi }\end{array}$ & 22 & 14 & 6 & 0 \\
\hline Tersedak atau mual pada saat perawatan & 8 & 24 & 10 & 0 \\
\hline Rontgen foto & 41 & 0 & 1 & 0 \\
\hline $\begin{array}{l}\text { Alat untuk isolasi kerja, seperti kapas atau } \\
\text { penghisap ludah }\end{array}$ & 38 & 4 & 0 & 0 \\
\hline Mulut yang lelah karena terus terbuka & 27 & 13 & 2 & 0 \\
\hline Semprotan udara yang membuat gigi sakit & 14 & 21 & 7 & 0 \\
\hline $\begin{array}{l}\text { Informasi tentang tindakan yang dilakukan tidak } \\
\text { tepat }\end{array}$ & 13 & 20 & 9 & 0 \\
\hline Perawatan saluran akar & 3 & 22 & 17 & 0 \\
\hline Pencabutan gigi & 13 & 9 & 20 & 0 \\
\hline Takut terluka / trauma & 10 & 10 & 22 & 0 \\
\hline Merasa cemas secara tiba - tiba & 17 & 17 & 8 & 0 \\
\hline $\begin{array}{l}\text { Tidak dapat menghentikan dokter gigi ketika } \\
\text { perawatan }\end{array}$ & 20 & 16 & 6 & 0 \\
\hline Merasa tidak bebas untuk bertanya & 25 & 12 & 5 & 0 \\
\hline $\begin{array}{l}\text { Tidak dapat mendengarkan penjelasan dokter } \\
\text { dengan focus }\end{array}$ & 28 & 9 & 5 & 0 \\
\hline Di kritik, di ejek dan dinasehati oleh orang tua & 35 & 4 & 3 & 0 \\
\hline Aroma pada ruangan perawatan & 25 & 15 & 2 & 0 \\
\hline $\begin{array}{l}\text { Mendapatkan perawatan gigi yang membutuhkan } \\
\text { waktu lama }\end{array}$ & 14 & 18 & 10 & 0 \\
\hline Biaya perawatan gigi yang dibutuhkan & 32 & 7 & 3 & 0 \\
\hline $\begin{array}{l}\text { Pada saat menunggu nomor antrian sebelum } \\
\text { perawatan dan lamanya waktu perawatan }\end{array}$ & 29 & 8 & 5 & 0 \\
\hline Malu akan kondisi mulut & 28 & 10 & 4 & 0 \\
\hline Merasa dibatasi dan tidak dapat mengontrol diri & 24 & 14 & 4 & 0 \\
\hline
\end{tabular}

Dari tabel di atas dapat dilihat bahwa 52,4\% (22 orang) siswa/i kelas V - B SD St. Antonius Jl. Sriwijaya No.7 Medan tahun 2014 sangat cemas akan terjadi luka pada rongga mulut, 47,5\% (20 orang) sangat cemas terhadap tindakan pencabutan gigi dan penyuntikan. Sedangkan $97,6 \%$ (41 orang) tidak cemas pada tindakan foto rontgen, 90,4\% (38 orang) tidak cemas pada isolasi kerja pada saat mendapatkan perawatan dan $83,3 \%$ (35orang) yang merasa tidak cemas mendengarkan kritik pada saat mendapatkan perawatan.
Tabel A.3 Distribusi Frekuensi Jenis Pelayanan Kesehatan Gigi Dan Mulut Yang Paling Ditakuti Oleh Siswa/I Kelas V - B SD St. Antonius Jl. Sriwijaya No. 7 Medan Tahun 2014

\begin{tabular}{|c|c|c|c|c|}
\hline \multirow{3}{*}{ Jenis Kecemasan } & \multicolumn{4}{|c|}{ Tingkat Kecemasan } \\
\hline & 1 & 2 & 3 & 4 \\
\hline & $\begin{array}{c}\text { Tidak } \\
\text { Cemas }\end{array}$ & Cemas & $\begin{array}{l}\text { Sangat } \\
\text { Cemas }\end{array}$ & $\begin{array}{l}\text { Tidak } \\
\text { Tahu }\end{array}$ \\
\hline Pengukuran kedalaman gusi & 14 & 22 & 6 & 0 \\
\hline $\begin{array}{l}\text { Suara atau perasaan ngilu } \\
\text { pada saat membersihkan } \\
\text { gigi }\end{array}$ & 22 & 14 & 6 & 0 \\
\hline $\begin{array}{l}\text { Suara atau getaran bur } \\
\text { (pada saat penambalan ) }\end{array}$ & 17 & 20 & 5 & 0 \\
\hline Perawatan saluran akar & 3 & 22 & 17 & 0 \\
\hline Pencabutan gigi & 13 & 9 & 20 & 0 \\
\hline
\end{tabular}


Dari tabel di atas dapat dilihat bahwa 47,2\% ( 20 orang ) siswa/i kelas V - B SD St. Antonius Jl. Sriwijaya No.7 Medan tahun 2014 sangat cemas pada tindakan pencabutan gigi dan hanya 52,3\% (22 orang) siswa/i kelas $\mathrm{V}-\mathrm{B}$ yang tidak cemas pada tindakan pembersihan gigi.

\section{PEMBAHASAN}

Sebagian besar siswa/i kelas V - B SD St. Antonius Jl. Sriwijaya No. 7 Medan tahun 2014 memiliki tingkat kecemasan yang tinggi terhadap pelayanan kesehatan gigi yaitu 33,3\% (14 orang). Hanya 11,9\% (5 orang) yang tidak merasa cemas. Hasil yang diperoleh ini tidak jauh berbeda dibandingkan dengan penelitian sebelumnya tentang rasa takut anak terhadap pelayanan kesehatan gigi dan mulut di Puskesmas Bali Barat. Dari 91 orang yang menjadi sampel diperoleh hasil 8,79\% takut terhadap semua tindakan perawatan gigi, $85,73 \%$ menyatakan takut terhadap beberapa tindakan perawatan gigi dan hanya 5,49\% yang tidak takut terhadap perawatan gigi.

Penyebab kecemasan paling tinggi yang ditemukan pada siswa/i kelas V - B SD St. Antonius Jl. Sriwijaya No.7 Medan adalah terjadi luka pada rongga mulut yaitu $52,4 \%$ (22 orang) dan $97,6 \%$ (41 orang) merasa tidak cemas pada saat melakukan foto rontgen. Luka atau trauma pada rongga mulut anak dapat menjadi peristiwa yang sangat menjengkelkan dan menakutkan bagi anak dan orang tuanya. Cedera yang melibatkan fraktur atau kehilangan gigi depan dapat mengakibatkan efek emosional yang tidak sebanding dengan keseriusan cedera. Anak-anak yang sebelumnya ekstrovert dapat menjadi rendah diri karena penampilan mereka dan enggan untuk tersenyum (Parkin, S 1991).

Dari berbagai jenis pelayanan kesehatan gigi dan mulut (promotif, preventif dan kuratif) yang paling dicemaskan oleh siswa/i kelas V - B SD St. Antonius Jl. Sriwijaya No.7 Medan adalah tindakan pencabutan gigi dan penyuntikan yaitu $47,6 \%$ (20 orang) dan $52,3 \%$ (22 orang) tidak merasa cemas pada saat pembersihan gigi.

Hal ini dapat terjadi karena banyak orang tua yang memberikan pandangan bahwa unit pelayanan kesehatan gigi dan mulut merupakan hukuman bagi anak. Misalnya apabila anak malas untuk menyikat gigi maka anak di ancam akan dibawa ke dokter gigi untuk di suntik atau di cabut giginya. Pandangan ini yang dapat membentuk pola pikir anak yang menganggap mereka tidak perlu ke unit pelayanan kesehatan gigi dan mulut apabila tidak membuat suatu kesalahan (Ramadhan A, 2010).

\section{Simpulan}

Dari penelitian yang telah dilakukan pada siswa/i kelas V-B SD St. Antonius Jl. Sriwijaya No. 7 Medan tahun 2014 tentang gambaran tingkat kecemasan anak terhadap pelayanan kesehatan gigi dan mulut dapat disimpulkan :

1. Sebanyak $33,3 \%$ ( 14 orang ) siswa/i kelas V - B SD St. Antonius Jl. Sriwijaya No. 7 Medan tahun 2014 memiliki tingkat kecemasan yang tinggi terhadap pelayanan kesehatan gigi dan mulut dan hanya $11,9 \%$ (5 orang) yang tidak cemas sama sekali terhadap pelayanan kesehatan gigi dan mulut.

2. Hal-hal yang menjadi faktor penyebab kecemasan pada siswa/i kelas V-B SD St. Antonius Jl. Sriwijaya No.7 Medan tahun 2014 terhadap pelayanan kesehatan gigi dan mulut adalah $52,4 \%$ (22 orang) sangat cemas terhadap luka yang terjadi dalam rongga mulut, $47,5 \%$ (20 orang) sangat cemas terhadap tindakan pencabutan gigi dan penyuntikan. Sedangkan $97,6 \%$ (41 orang) tidak cemas pada tindakan foto rontgen, 90,4\% (38 orang) tidak cemas pada isolasi kerja pada saat mendapatkan perawatan dan $83,3 \%$ (35 orang) yang merasa tidak cemas mendengarkan kritik pada saat mendapatkan perawatan.

3. Jenis pelayanan kesehatan gigi dan mulut yang paling dicemaskan oleh siswa/i kelas V - B SD St. Antonius Jl. Sriwijaya No.7 Medan tahun 2014 adalah pencabutan gigi yaitu $47,2 \%$ (20 orang) dan yang paling sedikit menimbulkan kecemasan adalah tindakan pembersihan gigi $(52,4 \%)$

\section{Saran}

1. Kepada Pihak Sekolah SD St. Jl. Sriwijaya No.7 Medan

Diharapkan agar pihak sekolah memperkenalkan pelayanan kesehatan gigi dan mulut kepada siswa/i disekolah tersebut dalam program Usaha Kesehatan Gigi Sekolah (UKGS) ataupun program lainnya. Dengan demikian siswa/i tidak menganggap bahwa pelayanan kesehatan gigi dan mulut sebagai suatu hal yang perlu dicemaskan atau ditakuti. Dapat mendatangkan tenaga kesehatan gigi dan mulut ke sekolah minimal satu kali dalam setahun untuk melakukan pendekatan langsung dengan cara memberikan penyuluhan dan pemeriksaan gigi siswa/i.

2. Kepada Jurusan Keperawatan Gigi

Diharapkan agar lebih giat memberikan penyuluhan tentang pentingnya kesehatan gigi dan mulut dan menjelaskan jenis pelayanan yang dapat dilakukan untuk dapat merubah pola pikir dan menarik minat anak terhadap pelayanan kesehatan gigi dan mulut.

\section{DAFTAR PUSTAKA}

Andlaw, R.J., 1992. Perawatan Gigi Anak. Widya Medika : Jakarta

Anonim.http://dentistlove.blogspot.com/

Anonim.2010.http://repository.usu.ac.id/bistream/1234567 89/23642/3/Chapter\%201l.pdf

Anonim.2010.http://repository.usu.ac.id/bistream/1234 56789/23642/4Chapter\%201.pdf

Anonim.2011.http://tugaskuliah.wordpress.com/2011/12/1 1/kti-kesehatan-gigi-perasaan-takut-pada-anaksiswa-sd-dalam-melakukan-perawatan-gigil

Clarke,J.H.,1998.http://UniversitySchoolOfDentistry/Clark e,J.H.1998/Oregon HealthSciences/

Corah,N.http://www.scribd.com/doc/61745765/NormanCorah. 
Gani, A.H. , 2012. Dental Hypnosis. Widya Medika : Yogyakarta

Keneddy, D.B. , 1992. Konservasi Gigi Anak. EGC : Jakarta

Mashar, R. , 2011. Emosi Anak Usia Dini Dan Strategi Pengembangannya. Kencana : Jakarta

Notoadmodjo, S. , 2005. Promosi Kesehatan Teori Dan Aplikasi. Rineka Cipta : Jakarta

Cipta : Jakarta
Parkin, S.F., 1991. Notes In Paediatric Dentistry. Wright : Oxford

Ramadhan, A.G. , 2010. Serba Serbi Kesehatan Gigi Dan Mulut. Bukune : Jakarta

Rumpak, J.C. , dkk., 2005. Kamus Besar Bahasa Indonesia. Balai Pustaka : Jakarta

Saleh,N.,2013.http://nuraminsaleh.blogspot.com/2013/ 01/pengertian-kecemasan-menurut-para-ahli.html. 